\title{
Broad-Host Range Gene Transporter Particles Produced by Aliivibrio fischeri
}

\author{
Hiroshi Xavier ChiUrA ${ }^{1,2 *}$, NAmi UChiYAma ${ }^{1 \dagger}$, and KaZUhiro KogurE ${ }^{1}$ \\ ${ }^{1}$ Marine Microbiology Laboratory, Department of Marine Ecosystems Dynamics, Ocean Research Institute, University \\ of Tokyo, 1-15-1 Minamidai, Nakano-ku, Tokyo 164-8639, Japan; and 2 Arbeitsgruppe Allgemeine Mikrobiologie, \\ Zentrum für Anatomie und Zellbiologie, Medizinische Universität Wien, Währingerstr. 10, Wien A-1090, Austria
}

(Received August 5, 2009—Accepted October 20, 2009—Published online November 12, 2009)

Aliivibrio fischeri NCIMB1281 ${ }^{\mathrm{T}}$ (basonym, Vibrio fischeri) spontaneously started broad-host range vector particle (AfVP) production by budding from the logarithmic phase, and stabilised at around $7.0 \times 10^{10}-7.4 \times 10^{11}$ particles $\mathrm{mL}^{-1}$ without any accompanying change in the host population. AfVPs had a spherical shape and varied in diameter from 18.1 to $159.2 \mathrm{~nm}$ [median $\pm \mathrm{SD}, 58.4 \pm 11.9 \mathrm{~nm}, n=528$ ], with $95.1 \%$ between 30.2 and $84.6 \mathrm{~nm}$ in diameter exhibiting a normal distribution. Their buoyant density and DNA content ranged from 1.3607 to $1.3980 \mathrm{~g} \mathrm{~cm}^{-3}$, and 17.3 to 95.3 $\mathrm{kbp}$, respectively. Regardless of UV treatment, AfVPs enhanced the efficiency of plating 116-136\% at a multiplicity of infection of $c a .140$ in Escherichia coli AB1157. Generalised transduction was observed with a frequency of between $10^{-4}$ and $10^{-6}$ cells per AfVP without UV treatment. Upon infection, the particle membrane remained outside the recipient cell, and a string-like structure coated with a fibrous proteinaceous-like material was present. The growth of the E. coli transductant (AfV-E-trans) reached a maximum of $c a .415 \%$ that of the parental E. coli recipient. AfV-Etrans acquired the ability to produce budding particles.

Key words: broad-host range, horizontal gene transfer (HGT), serial transduction, Aliivibrio fischeri, VLP(s)

In environmental samples, particles similar in morphology to viruses are called virus-like particles (VLPs). Although virioplankton is the most abundant class of plankton in a variety of aquatic habitats $(2,12,21,23,30,32,33)$, studies on its behaviour in the environment are scarce. VLP-mediated transduction among microbes has become of interest to researchers in microbial ecology $(12,33,34)$, because of the possible impact VLPs could have on horizontal gene transfer (HGT). Virus-mediated HGT is considered one of the most important components of evolution and the genetic diversity in natural microbial communities, since virus-mediated gene transfer has had more effect on microbial populations than was previously considered (18). HGT for various gene clusters, such as drug resistance genes, has recently been reported based upon sequence analyses $(16,20)$. However, assessment of the degree of transduction in natural environments is still limited by insufficient experimental systems. The development of a technique of isolating VLPs from the environment may lead to new findings regarding gene transfer mediators (28).

We have demonstrated that VLPs released spontaneously into culture medium from some marine bacterial isolates show a gene transfer capability, with a lethal effect on recipients distantly related to their original host (3-5). These VLPs contain DNA, and are similar morphologically to viruses (35). We have proposed calling such particles "broad-hostrange vector particles" (VPs) because of their extraordinary properties. VPs only become apparent on electron microscopic (EM) observation, which reveals budding particles

\footnotetext{
* Corresponding author. E-mail: hxc@ori.u-tokyo.ac.jp; Tel: +81-35351-6535; Fax: +81-3-5351-6482.

† Present address: Quality Assurance Department, Q.P. Corporation, 2-5, Sengawa-cho, Chofu-shi, Tokyo 182-0002, Japan
}

generated using a recipient different from the sampled habitat. Hence, the proportion of VPs in the VLP fraction of environmental samples is unclear. VPs are postulated to randomly encapsulate a certain length of host chromosome through serial transductions (9). Regardless of UV irradiation, VPs exhibit a mildly lethal effect (maximum, 10\%) towards a taxonomically broad range of recipients without plaque formation. VPs $(3-10)$ do not fit the current concept of a "virus" with a narrow host range (1). Although the DNA-encapsulating system of VP is still unclear, these characteristics supports the possibility that VP-mediated transduction enhances microbial differentiation and evolution.

Recent developments in genome science have revealed that virus-mediated transduction is not only a phenomenon observed in the laboratory, but contributes to microbial evolution and differentiation.

A comparison of gene sequences between $\operatorname{lu} x A$ and its accessory fluorescent protein together with multilocus housekeeping genes among luminous bacteria of the genus Aliivibrio, done by Yoshizawa (35), has made clear that luciferase-related genes in some luminous strains were acquired from the genus Photobacterium. These findings suggest the spectral diversity in light emission to be generated by both divarication of the luciferase gene at the genus level and the acquisition of accessory fluorescent proteins. Although HGT would not be responsible for the speciation of luminous bacteria, it would probably be involved in the diversification of emitting light wavelengths shared at the order level. As is predicted from the sequence data $(15,30$, 35), HGT must have occurred for the spectral diversity in light emission to have evolved. All the factors necessary for the expression of functional genes in phylogenetically distant species must have been transferred. However, it is impractical to expect the transfer of all functional gene clusters to a 
recipient with the aid of conventional gene transfer schemes, since the maximum size of a dsDNA insert in existing gene transfer vectors such as plasmids and coliphage lambda is $<25 \mathrm{kbp}$ (plasmid: insert DNA maximum size $=15 \mathrm{kbp}$, phagemid: insert=25 kbp) (1). Thus, an aid capable of transferring a substantial functional gene cluster would be necessary. The possibility of specific particle production having a gene transfer capability was examined in a luminal marine bacterial type strain, Alivibibrio fischeri (29). Furthermore, the contribution of the HGT of chromosomal genes to the recipient Escherichia coli AB1157 at a high multiplicity of infection (MOI) was examined. The strain was shown to be capable of producing a broad-host gene transfer particle: AfVP, as described above.

\section{Materials and Methods}

Bacterial Strains, media, culture conditions, and cell and particle enumeration

Aliivibrio fischeri $\left(\mathrm{NCIMB} 1281^{\mathrm{T}}=\mathrm{ORI}\right.$ No. 194), originally isolated from a light organ of Euprymna scolopes, was selected from our laboratory collection. A. fischeri was cultured in ZoBell Marine Broth 2216E (Difco, Becton Dickinson, Sparks, MD, USA) and ZoBell Marine Agar $2216 \mathrm{E}$ (Difco) at $20^{\circ} \mathrm{C}$. The inoculum comprised $3.6 \times 10^{6}$ cells $\mathrm{mL}^{-1}$, and was incubated at $20^{\circ} \mathrm{C}$ for $315 \mathrm{~h}$ with shaking at $60 \mathrm{rpm}$. The total volume of the culture was $3.8 \mathrm{~L}$.

Cells were enumerated using samples fixed in $2 \%(\mathrm{v} / \mathrm{v})$ neutral-buffered formaldehyde (Merck, Darmstadt, Germany) on Anodisc $^{\mathrm{TM}} 47$ membrane filters (pore size $0.02 \mu \mathrm{m}$; Advantec Toyo Kaisha, Tokyo, Japan) and stained with SYBR ${ }^{\circledR}$ Gold (Molecular Probe, Invitrogen, Carlsbad, CA, USA), under an epifluorescence microscope (E600; Nikon, Tokyo, Japan) equipped with a super high-pressure mercury lamp with B excitation (450-490 nm) without an ND filter, at a magnification of $\times 1,000$. The number of bacteria was determined from a count exceeding four hundred individuals or 40 eye-fields.

Particles were enumerated by fixing a portion of sample with 10 $\mathrm{mM}$ EDTA containing $2.5 \%(\mathrm{v} / \mathrm{v})$ glutaraldehyde (Wako Pure Chemical Industries, Osaka, Japan) overnight at ambient temperature, and applying it to a carbon and parlodion-coated copper grid (150 mesh; Stork Veco International, Eerbeek, Netherlands) placed in an Epok 812 (Shell Chemicals, Harris Country, TX, USA)embedded-flat-bottomed ultracentrifugation tube and centrifuging at $46,000 \times \mathrm{g}$ for $90 \mathrm{~min}$ at $20^{\circ} \mathrm{C} \mathrm{(2)} \mathrm{using} \mathrm{a} \mathrm{Beckman} \mathrm{Preparative}$ Ultracentrifuge L8M with a SW 55.2 Ti rotor (Beckman-Coulter, Fullerton, CA, USA). Grids were stained with $2 \%(\mathrm{w} / \mathrm{v})$ uranyl acetate (Merck) for $30 \mathrm{~s}$, and then sequentially washed for $15 \mathrm{~s}$ with $0.2 \mu \mathrm{m}$-filtered deionised and distilled water, and $95 \%(\mathrm{v} / \mathrm{v})$ ethanol (Wako) twice.

Particle counts were made under a JEM-1200EX electron microscope (JEOL, Tokyo, Japan) at an accelerating voltage of $80 \mathrm{kV}$ and magnification of $\times 50,000$ as described $(2,7)$.

\section{Preparation and purification of virus-like particles}

The culture was spun down at 7,500 $\times \mathrm{g}$ for $40 \mathrm{~min}$ at $4^{\circ} \mathrm{C}$ using a Kubota RT20000 refrigerated centrifuge equipped with a RA-6 rotor (Kubota Medical Appliance Supply, Tokyo, Japan) to separate the cells and the supernatant. The cell pellet was subjected to serial rinsing with TBT $[100 \mathrm{mM}$ Tris- $\mathrm{HCl}, 100 \mathrm{mM} \mathrm{NaCl}$, and $10 \mathrm{mM}$ $\mathrm{MgCl}_{2}, \mathrm{pH} 7.4$; Wako] buffer twice, and centrifugation $(8,000 \times g$, $15 \mathrm{~min}, 4^{\circ} \mathrm{C}$ ), then stored in a deep freezer at $-85^{\circ} \mathrm{C}$ until in situ lysis for Crossfield gel electrophoresis. The rinsing obtained as the supernatant was combined with the above the culture supernatant (total volume, $c a .4 \mathrm{~L}$ ), filtered with a $0.2-\mu \mathrm{m}$ membrane filter (CCS-020-E1H, Advantec), and concentrated with Minitan Ultrafiltration Systems using a $100 \mathrm{kDa}$ cut-off membrane (Minitan;
Millipore, Bedford, MA, USA), to $c a .15 \mathrm{~mL}$. Free nucleic acid and protein levels were monitored by reading absorbance at $260 \mathrm{~nm}$ and $280 \mathrm{~nm}$ using a spectrophotometer (Type UV260; Shimadzu, Kyoto, Japan). The concentrated specimen was dialysed against 6 changes of $0.25 \mathrm{~L}$ of $10 \mathrm{mM}$ potassium phosphate buffer saline [ $5 \mathrm{mM} \mathrm{MgCl}_{2}$, and $200 \mathrm{mM} \mathrm{NaCl}$ supplemented phosphate buffer, $\mathrm{pH}$ 7.0], then treated with $10 \mu \mathrm{g} \mathrm{mL} \mathrm{m}^{-1}$ each of DNase I and RNase A (Sigma-Aldrich, St. Louis, MO, USA) at $25^{\circ} \mathrm{C}$ overnight, and finally placed at $80^{\circ} \mathrm{C}$ for 15 min to inactivate DNase. The treated specimen was spun down at $88,000 \times \mathrm{g}$ for $40 \mathrm{~min}$ at $4^{\circ} \mathrm{C}($ Beckman Preparative Ultracentrifuge L8M equipped with a 55.2Ti rotor) to obtain a particle pellet, which was re-suspended in $500 \mu \mathrm{L}$ of TBT buffer, and dispersed in $5 \mathrm{~mL}$ of $35 \%$ (w/v) $\mathrm{CsCl}$ (Boehringer Mannheim, Mannheim, Germany) in TBT. After CsCl-density gradient equilibrium ultracentrifugation at $178,000 \times \mathrm{g}$ for $18 \mathrm{~h}$ at $4^{\circ} \mathrm{C}$, bands containing particles were recovered by a side puncture technique (17). Buoyant densities $\left(\rho^{25}\right)$ of the bands were determined with an Abbe-refractometer (Atago Seisakusho, Tokyo, Japan), and then specimens were placed in Spectra/Por 4 (molecular weight cut off, MWCO $=12,000-14,000$; Spectrum Chemicals Mfg, Houston, TX, USA) tubes, and dialysed against 6 changes of $0.25 \mathrm{~L}$ of $10 \mathrm{mM}$ phosphate buffer $(\mathrm{pH} 7.0)$ at $4{ }^{\circ} \mathrm{C}$ to remove $\mathrm{CsCl}$. This purified particle is referred to as AfVP, and was used for subsequent experiments.

The nucleic acid and protein contents of the specimens were determined photometrically as above. Protein content was also determined using a Protein Assay Kit (Bio-Rad Laboratories, Hercules, CA, USA) according to its specifications for micro assays.

Preparation of the recipient, Escherichia coli AB1157, for the gene transfer experiment

Seed cultures of the recipient E. coli $\mathrm{AB} 1157$ ( $\mathrm{F}^{-} ;$thr-1 leuB6 thi-1 lacY1 galK2 ara-14 xyl-5 mtl-1 proA2 his-4 argE3 rpsL31 tsx-33 supE44), obtained from the National Institute of Genetics, Shizuoka, Japan, were prepared as described previously (10). After confirmation of respective markers, the recipient was grown to $c a$.

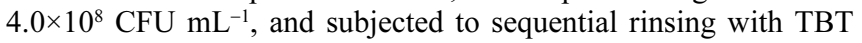
buffer and centrifugation $\left(7,500 \times \mathrm{g}, 40 \mathrm{~min}, 4^{\circ} \mathrm{C}\right)$ twice. The rinsed cells were re-suspended in 7\% (v/v) glycerine (Merck)-containing TBT buffer, dispensed as $1-\mathrm{mL}$ aliquots, immediately frozen in liquid nitrogen, and stored at $-85^{\circ} \mathrm{C}$ prior to use.

\section{AfVP-mediated gene transfer to Escherichia coli AB1157}

The transduction experiment was carried out as described (5). Briefly, the selection medium was based upon the minimal medium of Davis [MM (\%, w/v): $0.2 \% \quad \mathrm{KH}_{2} \mathrm{PO}_{4}, 0.7 \% \mathrm{~K}_{2} \mathrm{HPO}_{4}, 1.0 \%$ $\left(\mathrm{NH}_{4}\right)_{2} \mathrm{SO}_{3}, 0.05 \%$ sodium citrate (Kyowa Hakko Kogyo, Tokyo, Japan), $0.01 \% \mathrm{MgSO}_{4}, 0.2 \%$ glucose and $1 \mu \mathrm{g} \mathrm{mL}^{-1}$ thiamine, $1.5 \%$ (w/v) agar (Wako, reagent grade)] supplemented with three out of four amino acids [final concentration: $20 \mu \mathrm{g} \mathrm{mL}^{-1}$ leucine, proline, histidine, arginine]. All media used for the cultivation of E. coli AB1157 were supplemented with $100 \mu \mathrm{g} \mathrm{mL}^{-1}$ of streptomycin (Meiji Seika, Tokyo, Japan).

Recipient cells, E. coli AB1157 $\left(5.33 \times 10^{7}\right)$, were mixed with AfVPs to obtain a multiplicity of infection (MOI) of 10 , and left undisturbed for $30 \mathrm{~min}$ at $30^{\circ} \mathrm{C}$. A portion of the mixture withdrawn at $15 \mathrm{~min}$ after initiation was fixed with $2.5 \%(\mathrm{v} / \mathrm{v})$ glutaraldehyde, and particles and cells were counted by EM to determine the practical MOI.

For the examination of lethality, $100 \mu \mathrm{L}$ of a $10^{5}$-fold dilutant with TBT buffer was plated in triplicate in LB plates (17) with the over layer method with $0.6 \%$ TBT agar, and incubated for $1 \mathrm{~d}$ at $30^{\circ} \mathrm{C}$.

For the examination of gene transfer, the original mixture (100 $\mu \mathrm{L})$ was plated in the selection medium and incubated for $5 \mathrm{~d}$ at $30^{\circ} \mathrm{C}$. Two controls were included: 1 , recipient cells with TBT buffer instead of AfVPs to determine the spontaneous revertant rate; 2, ultraviolet light (UV)-treated AfVPs and recipient cells. For UV treatment, $400 \mu \mathrm{L}$ of an AfVP suspension $\left(4.0 \times 10^{11}\right.$ particles $)$ was 
placed in a quartz container with a water column thickness of $2 \mathrm{~mm}$, and irradiated with a 12-W UV sterilising lamp (CosmoBio, Tokyo, Japan) for $15 \mathrm{~min}$ from a distance of $10 \mathrm{~cm}$. As a reference, the same UV irradiation resulted in a reduction in the plaque-forming ability of coliphage T4 $\left(2 \times 10^{9} \mathrm{PFU} \mathrm{mL}^{-1}\right)$ by seven orders of magnitude $\left(2 \times 10^{2} \mathrm{PFU} \mathrm{mL}^{-1}\right)$.

Colonies generated in the respective selection medium were transferred with a sterile tooth pick to all other unselected marker plates, and cultured for $5 \mathrm{~d}$ at $30^{\circ} \mathrm{C}$, from which results co-ordinated marker transfer was determined. The gene transfer potential of AfVPs could be estimated from this result, since a single infection cannot result in colonies with co-ordinated marker transfer. Furthermore, the gene transfer capability of AfVP can be inferred in relation to the surface exclusion (1) at such a high MOI.

The growth profile of generated colonies was examined in LB broth at $30^{\circ} \mathrm{C}$ with shaking at $60 \mathrm{rpm}$.

\section{Electrophoretic analysis of nucleic acid species encapsulated} in AfVPs

AfVPs and $A$. fischeri cells were embedded in $1.0 \%(\mathrm{w} / \mathrm{v})$ agarose (SeaKem ME; FMC, Philadelphia, PA, USA) gel plugs. An in situ lysis method (8) was adopted, and Crossfield agarose gel electrophoresis was conducted (Crossfield AE-6800; ATTO, Tokyo, Japan). The gel plug was embedded in $1.5 \%(\mathrm{w} / \mathrm{v})$ agarose, and the gel was run using $0.5 \times \mathrm{TBE}$ buffer $(45 \mathrm{mM}$ Tris-borate, 2 mM EDTA, pH 8.0; Wako) at $14.3 \mathrm{~V} \mathrm{~cm}^{-1} ; 200 \mathrm{~mA}$; alternate angle, $110^{\circ}$; alternate time, $30 \mathrm{~s}$; at $12^{\circ} \mathrm{C}$ for $14 \mathrm{~h}$. Nucleic acid species were visualized by staining the gel with a 10,000 -fold dilution of SYBR ${ }^{\circledR}$ Gold stock solution in $0.5 \times \mathrm{TBE}$ buffer at $20^{\circ} \mathrm{C}$ for $1 \mathrm{~h}$, then illuminated on a Spectroline Trans Illuminator Model TC365A (Spectronics, Westbury, NY, USA) at $365 \mathrm{~nm}$. Results were recorded with an Olympus E1 single-lens reflex digital camera (Olympus, Tokyo, Japan).

\section{Results}

\section{Aliivibrio fischeri cell growth and particle production}

As shown in Fig. 1, A. fischeri entered a logarithmic phase of growth for up to $12 \mathrm{~h}$ immediately after the initiation of culture showing a generation time of $c a .1 .84 \mathrm{~h}$, and then entered a stationary phase, in which cell abundance stabilised at $c a .1 .2 \times 10^{9}$ cell $\mathrm{mL}^{-1}$ until the end of the culture. Initiation the production of particles, referred to as AfVPs, by budding (Fig. 1E) deduced from the particle per cell ratio and particle induction frequency (Fig. 1B and D) occurred $c a .15 \mathrm{~h}$ after initiation. The numbers of free particles continued to increase up to $c a .50 \mathrm{~h}$ after initiation, and then stabilised at $1.20 \times 10^{10}$ particles $\mathrm{mL}^{-1}$. Three sharp peaks $(24 \mathrm{~h}, 100 \mathrm{~h}$, and $200 \mathrm{~h}$ ) of induction were recorded, while no marked change in the cell population was observed to the end of culture. The average number of mature AfVP particles per cell was $c a .3$ (average \pm SD , $3.0 \pm 0.9, n=475$; see Fig. 1C). As shown in Fig. $1 \mathrm{E}$, cells with budding particles and other particles were heavily surrounded by mucoidal substances. Budding particles from the cells showed a clear boundary of dense inclusion bodies.

\section{Characteristics of AfVPs observed during purification}

From $315 \mathrm{~h}$ into the culture of $A$. fischeri, $3.40 \times 10^{15}$ particles in total $(100 \%)$ were recovered from the broth supernatant by centrifugation $\left(7,800 \times \mathrm{g}, 40 \mathrm{~min}, 4^{\circ} \mathrm{C}\right)$. AfVP production was accompanied by mucoidal substances (Fig. 1E, Dull shape of particles surrounding the cell), a trait observed in marine strains $(3,5)$, which reduced the rate of recovery
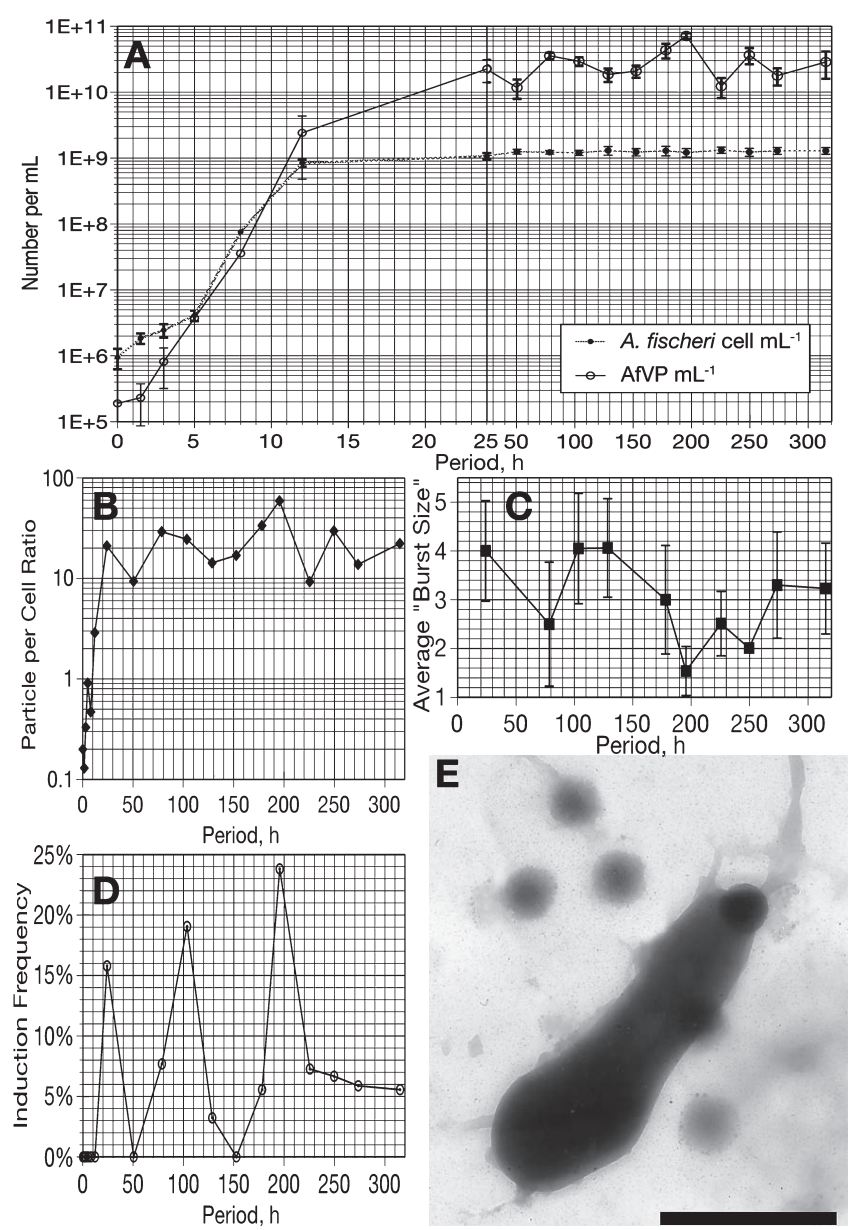

Fig. 1. Growth profile of Aliivibrio fischeri with specific reference to particle per cell ratio and induction frequency. (A) Growth profile: $\mathbf{O}$, cells $\mathrm{mL}^{-1} ; \bigcirc$, particles $\mathrm{mL}^{-1}$. (B) $\diamond$, Change in particle per cell ratio during the culture. (C) $\square$, Change in "burst size" during the culture. Average number of particles produced is $c a$. 3 (mean $\pm \mathrm{SD}, 3.0 \pm 0.9$, $n=475)$. (D) $\odot$, Change in induction frequency. Induction frequency is given as the fraction of AfVP-bearing cells in the total cell population by EM count. (E) Budding production of AfVPs from a $c a$. $170 \mathrm{~h}$ incubated $A$. fischeri cell surrounded by mucoidal substances, in which free particles are embedded. Scale bar, $500 \mathrm{~nm}$.

using a tangential flow concentration system $(0.2 \mu \mathrm{m}>$ particle $>100 \mathrm{kDa})$. Namely, $1.08 \times 10^{15}$ particles were recovered, corresponding to $39 \%$ of the initial number. $\mathrm{CsCl}$ densitygradient equilibrium ultracentrifugation resulted in $1.07 \times 10^{15}$ particles $(28 \%)$. Nucleic acid and protein contents of AfVP in the final specimen were $4.010 \mathrm{mg}$ and $101.764 \mathrm{mg}$, which corresponded to $29.8 \%$ and $35.8 \%$ of the initial values, respectively. The ratio of protein per nucleic acid was 24.9 , comparable to values reported to date $(3,5-10)$. Another feature of AfVP is its coagulating behaviour. As often found under EM, AfVPs formed clusters, which could be dispersed by adding EDTA, whose titration point to release entire particles was $6.7 \mathrm{mM}$.

The buoyant density $\left(\rho^{25}\right)$ of AfVP was between 1.3443 and $1.3980 \mathrm{~g} \mathrm{~cm}^{-3}$ (Fig. 2A). AfVPs had a spherical structure (Fig. 1E), 18.1 to $159.2 \mathrm{~nm}(n=627)$ in diameter. The range between 30.2 and $84.6 \mathrm{~nm}$ (95.1\% of the overall population) showed a standard probability curve (statistic: D'AgostinoPeason and Jaque-Bera, significance level, 5\%) with a con- 

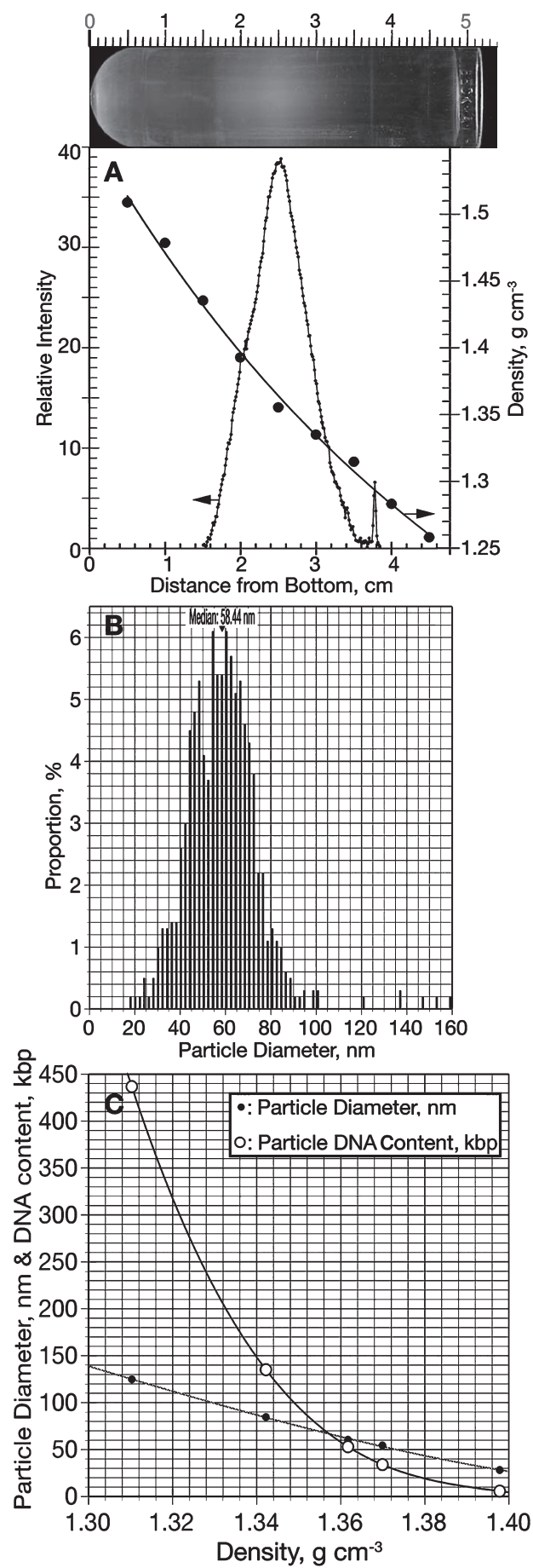

Fig. 2. $\mathrm{CsCl}$ density gradient equilibrium ultracentrifugation profile of AfVPs produced by Aliivibrio fischeri NCIMB $1281^{\mathrm{T}}$.

(A) Superimposed photo placed above shows the result of ultracentrifugation. Trend curve shows relation between ultracentrifuge tube's distance from bottom and buoyant density (right axis). Relative intensity (left axis) of particle sedimentation profile of the photo as a Gray value obtained by subtracting the background using ImageJ, which is available from the public domain (http://rsbweb.nih.gov/ij/), draws single normal probability distribution. (B) Size distribution of AfVPs showed a standard probability curve (statistic, D'Agostino-Peason and JaqueBera, significance level $=5 \%$ ) with a continual increase in diameter. (C) Relationship between buoyant density versus particle diameter, and encapsulated dsDNA in a particle. Capacity of the particle was obtained at a known packed ratio of dsDNA such as Coliphages T4, lambda and p1 $(1,5)$. The trend line was drawn by combining other findings for VP $(3,5-6,8,10)$ with the present data. $\bigcirc$, particle diameter in $\mathrm{nm}$; -, DNA content of the particle in kbp. tinual increase in diameter. The major proportion consisted of particles 40.3 to $76.6 \mathrm{~nm}$ in diameter [ $84.2 \%$ of the overall particle population (median $\pm \mathrm{SD}, 58.4 \pm 11.9 \mathrm{~nm}, n=528$ ), Fig. 2B], whose estimated DNA content in $\mathrm{kbp}$ would vary between 14.6 and 135.7 (Fig. 2C and 3A). The distribution of particle abundance in the sedimentation profile exhibited a similar continual increase with size, an apparent difference from findings concerning the size distribution of particles showing discrete bands, which were composed of several subpopulations (10).

The trend curve showing the relation between the distance of the ultracentrifuge tube from the bottom and buoyant density (Fig. 2A) is given as:

$$
\begin{aligned}
f_{\text {Bouyant density }}(d)=- & 0.0004 d^{3}+0.0087 d^{2}-0.0978 d+1.5605 \\
& \left(\mathrm{R}^{2}=0.999\right)
\end{aligned}
$$

Where: $d$ stands for distance from the bottom in $\mathrm{cm}$. As an extension (Fig. 2C), particle diameter and content as dsDNA would be expressed as the following functions of buoyant density $(\rho)$.

$$
\begin{gathered}
\begin{aligned}
& f_{\text {Particle diameter }}(\rho)= 14,027 \rho^{3}-53,695 \rho^{2}+67,125 \rho-27,197 \\
&\left(\mathrm{R}^{2}=0.999\right)
\end{aligned} \\
f_{\text {Particle DNA content }}(\rho)=-571,110 \rho^{3}+2,394,972 \rho^{2}-3,347,855 \rho+ \\
1,560,453\left(\mathrm{R}^{2}=0.999\right)
\end{gathered}
$$

Results of a nucleic acid type analysis using Crossfield agarose gel electrophoresis (Fig. 3A) gave bands in kbp between 7.4 and 125.8 from $A$. fischeri cells and 17.3 and 95.3 from AfVPs as encapsulated molecular mass as dsDNA (Fig. 3B), which accords well with that predicted from the empirical functions (see above, Fig. 2C). The major propor-

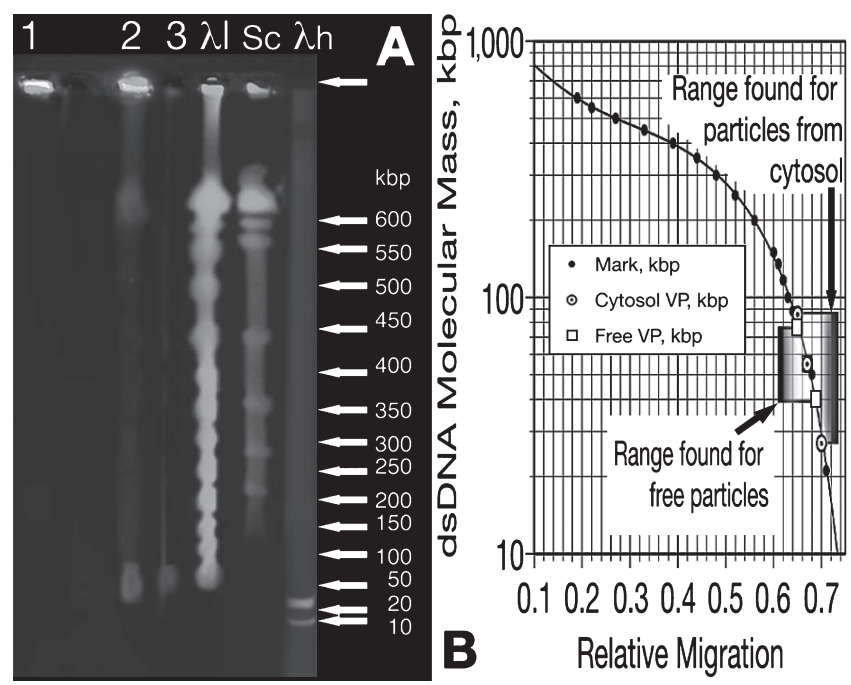

Fig. 3. Molecular type analysis of AfVP encapsulated nucleic acids, and translocation of AfVP content to the recipient cell.

(A) Nucleic acid species encapsulated in AfVPs: Lane 1, Recipient, Escherichia coli $\mathrm{AB} 1157$, as a negative control; Lane 2, $72 \mathrm{~h}$ cultured Aliivibrio fischeri cell; Lane 3, AfVP; Lane $\lambda 1$, Lambda ladder [48.5 kbp-1.2 Mbp, FMC]; Lane Sc, Saccharomyces cerevisiae chromosome [220 kbp-1 Mbp, Nippon Gene, Tokyo, Japan]; and Lane $\lambda \mathrm{h}, \lambda /$ HindIII [Nippon Gene]. (B) Trend line of dsDNA molecular mass for AfVP. Specific migration distance was obtained by comparing with the mass standards on the electrophoretogram using a densitogram created by ImageJ (http://rsbweb.nih.gov/ij/). 
tion of AfVPs, obtained as $\rho^{25}=1.3560-1.3929 \mathrm{~g} \mathrm{~cm}^{-3}$, was used as the material to examine the lethal effect and gene transfer capability.

\section{AfVP-mediated gene transfer to an auxotrophic Escherichia coli}

The marker thr- 1 was not used because of its high rate of spontaneous reversion $\left(10^{-7}\right)(5)$. Fig. 4A shows an EM image of the AfVP particle content to be under translocation to recipient $E$. coli cytosol. Multiplicity of infection (MOI), the number of particles per cell, was originally designed to be 10 , but the observed MOI was actually 140.3. Despite such an extremely high MOI, no lethality in recipient $E$. coli AB1157 cells was observed. Results were expressed as efficiency of plating (EOP), with the number of colonies formed in TBT control plates taken as $100 \%$ (average \pm SD, $100 \pm 11 \%, n=9)$. The EOP of UV-treated AfVPs was $136 \pm 14 \%(n=9)$. That of untreated AfVPs was $116 \pm 39 \%$ $(n=9)$. In other words, AfVP was not lethal to the recipients regardless of UV-treatment. As a result of gene transfer mediated by AfVPs, amino acid deficiencies in the recipient $E$. coli were successfully restored. Transduction frequency is given as fraction of the generated colony number in each selected marker plate in the total applied particles $\left(1.81 \times 10^{5}\right.$ particles per plate). Spontaneous reversion frequencies were found to be below the level of detection for the markers employed. No gene transfer was detected in UV-irradiated AfVPs used as mediators. On the contrary, colonies formed in the respective selection medium were: $\operatorname{leu}^{+}, 27$; $\mathrm{pro}^{+}, 24$; his $^{+}, 1$; $\arg ^{+}, 48$; and MM plate without any amino acid requirements, 29. Result of co-ordinated marker determination revealed that every colony generated in any selected

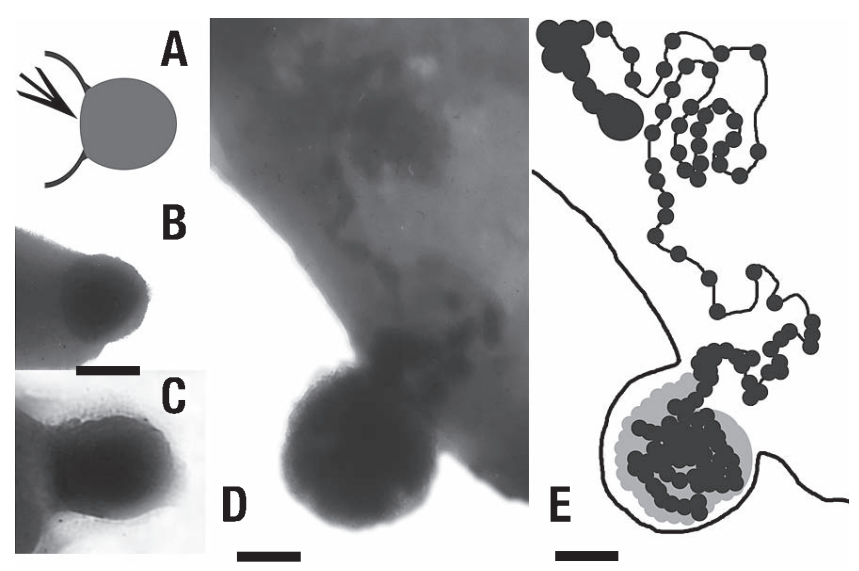

Fig. 4. Translocation of content from infecting AfVPs to recipient Escherichia coli with specific reference to budding particles from Aliivibrio fischeri and AfV-E-trans.

(A) Diagrammatical representation of particle budding from the cell surface. A discrete boundary can be seen around the budding particle as indicated by an arrow. (B) AfVP budding from $A$. fischeri. (C) Particle budding from AfV-E-trans, a transductant $E$. coli generated with the aid of AfVP-mediated transduction. (D) and (E) Translocation of content from infecting AfVPs to recipient E. coli. On transduction, a portion of AfVP and recipient mixture was fixed with $2.5 \%(\mathrm{v} / \mathrm{v})$ glutaraldehyde at $15 \mathrm{~min}$ after initiation and stood undisturbed for $3 \mathrm{~h}$ at ambient temperature to determine practical MOI. (D) shows EM image of $\mathrm{UV}^{-}$-AfVP infecting the recipient, and (E) is a diagrammatical representation of the translocation of $\mathrm{UV}^{-}$-AfVP content into the recipient. Scale bars, $100 \mathrm{~nm}$. marker plates exhibited growth in any unselected marker plates. Consequently, 129 transductant colonies, whose amino acid auxotrophy was totally restored, were obtained. Transduction frequency for the respective marker is estimated to be: leu $^{+}, 1.5 \times 10^{-4}$; pro $^{+}, 1.3 \times 10^{-4}$; his $^{+}, 5.5 \times 10^{-6}$; $\mathrm{arg}^{+}, 2.6 \times 10^{-4}$; and all amino acid requirements restored, $1.6 \times 10^{-4} \mathrm{CFU}$ per particle.

Particle production from the transductants, referred to as AfV-E-trans, grown in LB broth at $30^{\circ} \mathrm{C}$ was confirmed. AfV-E-trans acquired budding particle production as shown in Fig. 5B. Maximum growth, corresponding to $c a$. $415 \%$ of that of the parental E. coli recipient, was recorded at $170 \mathrm{~h}$ incubation.

\section{Discussion}

To extend our knowledge of "broad-host range gene transfer particles", a luminal marine bacterium, Aliivibrio fischeri, was examined for its ability to produce a specific particle having a gene transfer capability. This study may initiate effects to elucidate HGT, which is predicted from the sequence data (35).

The oscillating nature of the induction frequency was different from the particle production observed for other microbes taken from various water columns (3-8). The $c a$.

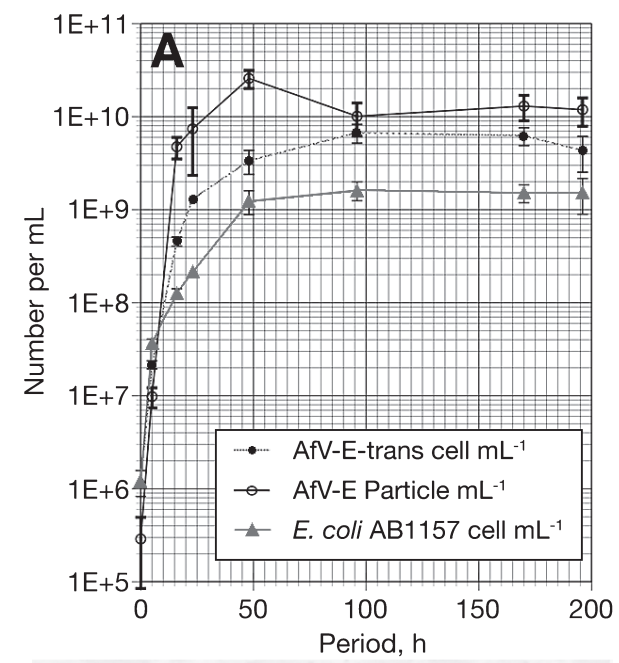

B

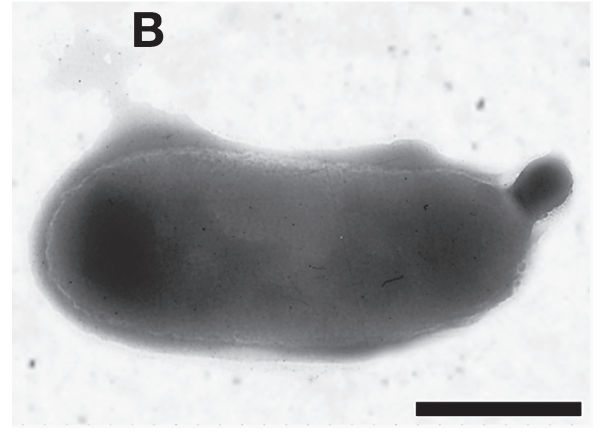

Fig. 5. Growth profile of AfVP-mediated Escherichia coli transductant (AfV-E-trans) with specific reference to parental E. coli AB1157 (number per $\mathrm{mL} \pm \mathrm{SD}, n=3$ ). (A) AfV-E-trans was cultured in LB medium at $30^{\circ} \mathrm{C}$ with shaking at $60 \mathrm{rpm}$. $\mathrm{O}$, AfV-E-trans cells $\mathrm{mL}^{-1}$; $\bigcirc$, particle $\mathrm{mL}^{-1} ; \boldsymbol{\Delta}, E$. coli AB1 157 cells $\mathrm{mL}^{-1}$. (B) Photo represents budding production of particles from $c a .48 \mathrm{~h}$ cultured AfV-E-trans cells. Scale bar, $500 \mathrm{~nm}$. 
$20 \%$ higher induction frequency shown by $A$. fischeri should have a positive effect on the survival of the strain, since the induction frequency for some marine strains of Alphaproteobacteria fell between 4 and $9 \%$ under comparable condition (5). As for the "burst size" of AfVPs, ca. 3 mature particles were observed in an induced cell (Fig. 1C), which is comparable to previous findings $(9,10)$. As no disrupted particles were observed during the periods corresponding to the decrease in particle per cell ratio (Fig. 1B), it is likely that particles in the broth would again be incorporated into the cells. Similar phenomena were observed for E. coli transductants (10) generated with the aid of particles collected from a geothermal vent at the Toyoha mine (19).

Predicted values for AfVP encapsulated dsDNA were comparable to that obtained from gel electrophoresis (Fig. 2C and 3).

In AfVP-mediated transduction, translocation of AfVP content to recipient $E$. coli cytosol was observed by EM as shown in Fig. 4D. It is likely that the particle membrane remains outside of the recipient cell, and the string-like structure coated with a proteinaceous material was unravelled as traced in Fig. 4E. Empirical findings make it possible to distinguish infecting particles from budding particles, since the boundary of infecting particle content is unclear. In contrast, budding particles show a clear boundary of its dense content (Fig. 4A-C). An observation done for similar particle production in a cell revealed that the host chromosomal DNA string was coated with a proteinaceous material, which was confirmed using a gold-labelled antibody $(11,31)$.

As for transduction frequency in marine environments, although the transduction frequency is intricate to estimations in situ, virus-mediated HGT has been documented in studies of freshwater and marine systems $(13,22,26)$. Jiang et al. (13) made an effort constructing an applicable transduction studies model system in marine environments. Consequently, applying several lysogenic phage-host systems isolated from Hawaiian coastal waters, transduction frequencies ranging from $1.3 \times 10^{-7}$ transductant $\mathrm{PFU}^{-1}$ (for laboratory assays) to $3.7 \times 10^{-8}$ transductant $\mathrm{PFU}^{-1}$ (for natural communities) either from wild-type strains or concentrates of natural marine bacterial communities as recipients (14) were found. Transduction frequencies reported to date, evaluated using either natural bacterial or viral communities, have varied from $10^{-8}$ to $10^{-5}$ per transducing particle $(33)$, of which the highest was documented by the authors $(5,6)$. We have suggested that such broad-host range VPs transferred genes through generalised transduction, since VPs from different sources showed similar gene transfer efficiency with respect to the genetic marker rescued $(3-7,10)$. From findings to date, the VP-mediated transductants acquired the ability to produce particles, and regenerated particles from the transductants had a lethal effect and were capable of gene transfer into the $E$. coli recipient $(3-7,10)$. In contrast, the current findings endorsed a further impact for HGT on marine environments because AfVPs were non-lethal to recipients of distant phylogeny together with inter-generic VP-mediated gene transfer. The transduction frequency of AfVPs was found to be higher by 2 to 3 orders of magnitude than that reported for naturally isolated transducing phages $(12,24,27,33)$, and almost comparable to our previous findings in marine environments $(5,6)$. This is the first demonstration of VPmediated HGT achieved experimentally between marine Alivibrio and enteric bacteria. Furthermore, extremely high co-ordinated marker transfer frequencies, implicated in concomitant gene translocation through multiple infection, would provide a clue for understanding the gene flux in marine environments.

The current results suggest that gene transfer occurred as generalised transduction, because comparable marker transfer frequencies were observed. Co-ordinated marker transfer examined for transductant colonies generated in selection media (100 colonies in total) revealed that all the transductants formed colonies on all other unselected marker plates, namely, the co-ordinated marker transfer frequency was $100 \%$. Apparently, supplementary genes, which were additionally translocated to the recipient by AfVP multiple infection, were not excluded, but successfully expressed in the transductant (1). In principle, the analysis of genetic coordinated marker transfer has arisen from classical genetics of monozygotic crosses (1). Transduction-like gene transfer mediated by AfVPs is somewhat unusual, because additional incorporation in multiple particles seems to promote recipient viability. To estimate the occurrence of transductants with prototrophic reversion of all the four markers adopted, the following approximation was attempted. On the basis of particle volume and coliphage T4 DNA packed ratio $\left(2.34 \times 10^{-24} \mathrm{~L} \mathrm{bp}^{-1}\right)$, AfVPs would encapsulate linear dsDNA from $1.3 \mathrm{kbp}$ to $902.7 \mathrm{kbp}$. A major proportion (ca. 84\%) of the particle would encapsulate $14.7 \mathrm{kbp}$ to $100.5 \mathrm{kbp}$, whose diameter varied from $40.3 \mathrm{~nm}$ to $76.6 \mathrm{~nm}$. Although AfVPs varied in size, supposing that the major proportion consisted of a median particle size of $58.4 \mathrm{~nm}$, the dsDNA content of the particles is estimated at $44,665 \mathrm{bp}$. Distance in bp between adopted respective $E$. coli biochemical marker orthologues on A. fischeri chromosome 1 exceeds the content, which could be encapsulated in one particle: $\operatorname{argE3}-$ his $G 4=1,478,467$; hisG4-proA2=313,679; proA2-leuB6= 508,637; and leuB6- $\operatorname{argE3}=606,441$ according to $V$. fischeri ES114 genome sequence (25). Consequently, it could be hardly expect that a substantial proportion of AfVPs applied would be particles with genetic resources covering all the biochemical markers to be restored in a recipient at a single infection. However, current transduction experiments resulted in transductants with all the adopted markers restored to prototropy. Therefore, additional incorporation in multiple "infections" of a recipient without any hindrance during transduction is indispensable for generating transductants.

The E. coli transductant successfully acquired the ability to produce particles (Fig. 5). It is notable that the extent of transductant growth was much enhanced in comparison with that of the mother strain, E. coli AB1157. A distinctive difference is apparent for the transducing particles of typical bacteriophages, which contain a maximum of $1 \%$ of the host genome in frequency of $10^{-5}$ to $10^{-7}$ cells per particle and exhibits nearly $100 \%$ lethality (1) in recipient. The "production and incorporation trait" of the particle during the growth certainly endorsed the non-virulence of AfVPs in the transduction experiment. According to the growth profile, the proportion of free particles standing alone was rather scarce in 
the particle population, whereas the major proportion was observed as clustering bodies to make assemblages of more than 100 individuals. When such clustered particles were exposed to EDTA, the proportion of free particle increased as described above. In other words, gene transfer experiment under $10 \mathrm{mM} \mathrm{Mg}^{2+}$ may enhance the chance of the recipient incorporating multiple numbers of AfVPs. Under the circumstances, a high MOI (140) was applied in the gene transfer, which resulted in 129 transductants with all the markers reverted across the phylogenetic order from Vibrionales to Enterobacteriales with a considerably high transduction frequency.

Concerning HGT in Vibrionaceae: Kasai et al. (15) deduced from a lux operon sequence analysis that the operon and related gene clusters would have been horizontally transferred from Aliivibrio to Schwanella. Urbanczyk and colleagues (30) examined lux gene horizontal transfer in Vibrionaceae, and concluded that HGT routes based upon results of phylogenetic analyses were not substantially clear, and the contribution of HGT to the speciation would have been inadequate. Despite the prediction, sufficient updated findings are possible to upward revision. Phylogenetic analyses of the lux operon and related gene clusters, done by Yoshizawa (35), elucidated more frequent HGT than that ever considered in Vibrionaceae. In relation to this contemporary knowledge, accomplishment of HGT for lux operon and related gene clusters would be an inevitable consequence of a gene transfer scheme capable of huge gene cluster translocation with relaxed restrictions.

The current results suggest the horizontal transfer of regulatory gene assemblages to be accomplished by concomitant gene translocation and expression with the aid of non-virulent particles at a high MOI in nature. Together with noninhibitory effects of additional gene incorporation to the recipient, the trait of AfVP is separate from the conventional virus concept, and is likely to be an apparatus aimed for preservation of the host's chromosomal genes. As we reported, various functional gene clusters such as thermo-resistance was transferred to the $E$. coli mediated by VP (10). VP-mediated serial transduction supports an indispensable role in microbial differentiation and evolution as mentioned above.

\section{Acknowledgements}

This paper is dedicated to the memory of Mari Segawa, who thrived on arduous tasks as a student member of JSME at the beginning of VP-mediated HGT study.

The authors are grateful to S. Yoshizawa, B. Velimirov, R.W. Ridge, M. Nishimura, K. Inoue and 2 anonymous peer reviewers for critical reading, advice, thoughtful comments, and useful suggestions on the manuscript. The authors' research presented here was supported in part by Grant-in-Aid for Scientific Research No. 16310031 from the Japan Society for the Promotion of Science (JSPS), and funded partly by Donations to Encourage Research by Kyowa Hakko Kogyo Ltd and Life Cycle Association Ltd to hxc. Last and certainly not least, thanks are given to the authors' families.

\section{References}

1. Birge, E.A. 1994. Bacterial and bacteriophage genetics. 3rd ed. Springer-Verlag, New York, USA.

2. Børsheim, K.Y., G. Bratbak, and M. Heldal. 1990. Enumeration and biomass estimation of planktonic bacteria and viruses by transmission electron microscopy. Appl. Environ. Microbiol. 56:352-356.

3. Chiura, H.X., and J. Takagi. 1994. Phage-like particles production and gene transfer by marine bacteria. Bull. Jap. Soc. Microb. Ecol. 9:74-90.

4. Chiura, H.X., K. Kato, and J. Takagi. 1995. Phage-like particles released by a marine bacterium. Wien. Mitteil. 128:149-157.

5. Chiura, H.X. 1997. Generalized gene transfer by virus-like particles from marine bacteria. Aquat. Microb. Ecol. 13:74-85.

6. Chiura, H.X., B. Velimirov, and K. Kogure. 2000. Virus-like particles in microbial population control and horizontal gene transfer in aquatic environments, p. 167-173. In C.R. Bell, M. Brylinsky, and P. Johnson-Green (ed.), Microbial Biosystems: New Frontiers. Atlantic Canada Society for Microbial Ecology, Halifax, Canada.

7. Chiura, H.X. 2002. Broad host range xenotrophic gene transfer by virus-like particles from a hot spring. Microbes Environ. 17:53-58.

8. Chiura, H.X., H. Yamamoto, D. Koketsu, H. Naito, and, K. Kato. 2002. Virus-like particle derived from a bacterium belonging to the oldest lineage of the domain bacteria. Microbes Environ. 17:48-52.

9. Chiura, H.X. 2004. Novel broad-host range gene transfer particles in nature. Microbes Environ. 19:249-246.

10. Chiura, H.X., and M. Umitsu. 2004. Isolation and characterisation of broad-host range gene transporter particles from geo-thermal vent of Toyoha Mine. Microbes Environ. 19:20-30.

11. Chiura, H.X., and B. Velimirov. 2007. New serial transducing particles: Are we still missing the Essential?, p.45. In Concurrent Meeting: ISME Asian 2007 and the Annual Meeting of the Japanese Society Microbial Ecology, Matsuyama, Japan.

12. Fuhrman, J.A. 1999. Marine viruses and their biologeochemical and ecological effects. Nature 399:541-548.

13. Jiang, S.C., C.A. Kellogg, and J.H. Paul. 1998. Characterization of marine temperate phage-host systems isolated from Mamala Bay, Hawaii. Appl. Environ. Microbiol. 64:535-542.

14. Jiang, S.C., and J.H. Paul. 1998. Gene transfer by transduction in the marine environment. Appl. Environ. Microbiol. 64:2780-2787.

15. Kasai, S., K. Okada, A. Hoshino, T. Iida, and T. Honda. 2007. Lateral transfer of the lux gene cluster. J. Biochem. 141:231-237.

16. Kobashi, Y., A. Hasebe, M. Nishio, and H. Uchiyama. 2007. Diversity of tetracycline resistance genes in bacteria isolated from various agricultural environments. Microbes Environ. 22:44-51.

17. Maniatis, T., E.F. Fritsch, and J. Sambrook. 1982. Purification of bacteriophage $\lambda$, p. 80-84. In Maniatis, T., E.F. Fritsch, and J. Sambrook. (ed.), Molecular Cloning: A Laboratory Manual. Cold Spring Harbor Laboratory Press, New York, USA.

18. Miller, R.V., and G.S. Sayler. 1992. Bacteriophage-host interactions in aquatic system, p. 176-193. In E.M.H. Wellington and J.D. Van Elsas (ed.), Gene interactions among microorganisms in the natural environment, Pergamon Press, Oxford, UK.

19. Nakagawa, T., S. Hanada, A. Maruyama, K. Marumo, T. Urabe, and M. Fukui. 2002. Distribution and diversity of thermophilic sulfate-reduction bacteria within a $\mathrm{Cu}-\mathrm{Pb}-\mathrm{Zn}$ mine (Toyoha, Japan). FEMS Microbiol. Ecol. 1378:1-11.

20. Nonaka, L., K. Ikeno, and S. Suzuki. 2007. Distribution of tetracycline resistance gene, $\operatorname{tet}(\mathrm{M})$, in gram-positive and gramnegative bacteria isolated from sediment and seawater at a coastal aquaculture site in Japan. Microbes Environ. 22:355-364.

21. Paul, J.H., J.B. Rose, S.C. Jiang, and C. Kellog. 1993. Distribution of viral abundance in the reef environment of Key Largo, Florida. Appl. Environ. Microbiol. 59:718-724.

22. Paul, J.H. 1999. Microbial gene transfer. J. Mol. Microbiol. Biotechnol. 1:45-50.

23. Proctor L.M., and J.A. Fuhrman. 1990. Viral mortality of marine bacteria and cyanobacteria. Nature 343:60-62.

24. Replicon, J., A. Frankfater, and R.V. Miller. 1995. A continuous culture model to examine factors that affect transduction among Pseudomonas aeruginosa strains in freshwater environments. Appl. Environ. Microbiol. 61:3359-3366.

25. Ruby, E.G., M. Urbanowski, J. Campbell, et al. 2005. Complete genome sequence of Vibrio fischeri: A symbiotic bacterium with 
pathogenic congeners. Proc. Natl. Acad. Sci. USA 102:3004-3009.

26. Saye, D.J., and R.V. Miller. 1989. The aquatic environment: Consideration of horizontal gene transmission in a diversified habitat. p. 223-259. In S.B. Levy and R.V. Miller (ed.), Gene transfer in the environment. MacGraw-Hill, New York, USA.

27. Saye, D.J., O.A. Ogunseitan, G.S. Sayler, and R. V. Miller. 1990 Transduction of linked chromosomal genes between Pseudomonas aeruginosa strains during incubation in situ in a freshwater habitat. Appl. Environ. Microbiol. 56:140-145.

28. Takashima, Y., T. Yoshida, A. Kashima, S. Hiroishi, and K. Nagasaki. 2007. Cryopreservation of a myovirus infecting the toxin-producing cyanobacterium Microcystis aeruginosa. Microbes Environ. 22:297-299.

29. Urbanczyk, H., J.C. Ast, M.J. Higgins, J. Carson, and P.V. Dunlap. 2007. Reclassification of Vibrio fischeri, Vibrio logei, Vibrio salmonicida and Vibrio wodanis as Alivibrio fischeri gen. nov., comb. nov., Aliivibrio logei comb. nov., Aliivibrio salmonicida comb. nov. and Aliivibrio wodanis comb. nov., Int. J. Syst. Evol. Microbiol. 57:2823-2829.
30. Urbanczyk, H., J.C. Ast, A.J. Kaeding, J.D. Oliver, and P.V. Dunlap. 2008. Phylogenetic analysis of the incidence of lux gene horizontal transfer in Vibrionaceae. J. Bacteriol. 190:3494-3504.

31. Velimirov, B., H.X. Chiura, and K. Kogure. 2005. New transducing particles in the sea or are we still missing the essential? p. 249-250. In M. Che, G. Drazic and S. Fidler (ed.), Proceedings of 7th Multinational Congress on Microscopy. Slovene Society for Microbiology, Ljubljana, Slovenia.

32. Weinbauer, M.G., D. Fuks, and P. Peduzzi. 1993. Distribution of viruses and dissolved DNA along a coastal trophic gradient in the Northern Adriatic Sea. Appl. Environ. Microbiol. 59:4074-4082.

33. Weinbauer, M.G., and F. Rassoulzadegan. 2003. Are viruses driving microbial diversification and diversity? Environ. Microbiol. 6:1-11.

34. Wommack, K.E., and K.K. Colwell. 2000. Virioplankton: viruses in aquatic systems. Microbiol. Mol. Biol. Rev. 64:69-114.

35. Yoshizawa. S. 2009. Diversity of light emission spectra of marine luminous bacteria. Ph.D. thesis, University of Tokyo, Tokyo, Japan. 